
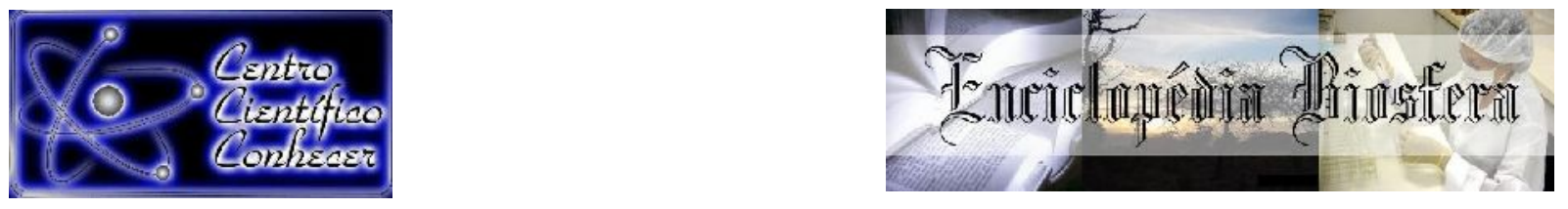

\title{
DISTRIBUIÇÃO DIAMÉTRICA DE ESPÉCIES NATIVAS DO CERRADO DE UMA RESERVA LEGAL EM RECUPERAÇÃO
}

\author{
Jaqueline Pinheiro da Silva ${ }^{1}$, Jhonatan Willian Moreira², Sybelle Barreira ${ }^{3}$
}

1 Doutoranda em Agronegócio na Universidade Federal de Goiás (UFG), Goiânia-GO, Brasil. E-mail: jaquelinepinheiro@discente.ufg.br

2 Graduando em Engenharia Florestal na Universidade Federal de Goiás, Goiânia-GO, Brasil.

3 Professora Doutora da Escola de Agronomia, departamento de Engenharia Florestal, da Universidade Federal de Goiás, Goiânia-GO, Brasil

Recebido em: 15/02/2021 - Aprovado em: 15/03/2021 - Publicado em: 30/03/2021

DOI: 10.18677/EnciBio_2021A16

\begin{abstract}
RESUMO
O novo Código Florestal Brasileiro entrou em vigor em 25 de maio de 2012, nele, as espécies exóticas podem ser intercaladas com espécies nativas em até $50 \%$ da reserva, em sistema agroflorestal, sendo dado o direito a exploração econômica das mesmas. Porém, poucos são os estudos que mostram que esse sistema consorciado possui benefícios tanto econômicos quanto ambientais. Sendo assim, este trabalho objetivou avaliar o potencial de crescimento em diâmetro de nove espécies nativas do bioma cerrado (Dipteryx alata; Genipa americana; Caryocar brasiliense; Hymenaea courbaril; Aspidosperma polyneuron; Handroanthus impetiginosus; Enterolobium maximum; Sterculia foetida e Copaifera langsdorffii) consorciadas em diferentes locais com quatro espécies exóticas (Eucalyptus sp; Tectona grandis; Acacia mangium e Hevea brasiliensis) para fins de recuperação de área, avaliando os possíveis ganho dos diferentes sistemas.
\end{abstract}

PALAVRAS-CHAVE: Bioma Cerrado, diâmetro, recuperação.

\section{DIAMETRIC DISTRIBUTION OF NATIVE SPECIES OF CERRADO IN A LEGAL RESERVES IN RECOVERY}

\begin{abstract}
The new Brazilian Forest Code, were approved in 25 May 2012, where the exotics can be interspersed with native species by up to $50 \%$ of the reservation in agroforestry system, and being given the right to economic exploration of the same. However, few studies have shown that intercropping system has both economic and environmental benefits. In this sense, the study sought to evaluate the growth potential in diameter nine native species of the Cerrado biome (Dipteryx alata; Genipa americana; Caryocar ENCICLOPÉDIA BIOSFERA, Centro Científico Conhecer - Jandaia-GO, v.18 n.35; p. 216 2021
\end{abstract}


brasiliense; Hymenaea courbaril; Aspidosperma polyneuron; Handroanthus impetiginosus; Enterolobium maximum; Sterculia foetida e Copaifera langsdorffii) consortiums in different locations with four exotic species (Eucalyptus sp; Tectona grandis; Acacia mangium e Hevea brasiliensis) for recovery areas, evaluating the possible gain of the different systems .

KEYWORDS: Cerrado Biome, diameter, recovery.

\section{INTRODUÇÃO}

As atuais formas de utilização dos ambientes do bioma Cerrado e de aproveitamento econômico das espécies na agricultura são extremamente precárias e degradantes. Presentemente, as principais ameaças à biodiversidade no Cerrado estão centradas na expansão da agricultura e da pecuária, exploração madeireira e queimadas. O Cerrado vem sofrendo ameaças devido a alterações antrópicas, aonde o agronegócio vem cada vez mais ganhando espaço, de baixos incentivos à conservação e proteção legal (STRASSBURG et al., 2017). De acordo com Carneiro e Costa (2016), grande parte da área do Cerrado atualmente é ocupada por pastagens, representando $30 \%$ da área total do bioma, enquanto a vegetação nativa ocupa $55 \%$ da área e outros $12 \%$ da área são ocupados por agricultura anual e perene. A expansão agrícola no Cerrado vem crescendo nos últimos anos e somente de 2000 a 2014, 26\% da área de vegetação nativa do Cerrado foi desmatada para uso agrícola (CARNEIRO; COSTA, 2016). Estima-se que o bioma deverá ser totalmente destruído até 2030, caso as tendências das ocupações continuem causando uma perda anual de 2,2 milhões de hectares de áreas nativas (MACHADO, 2016).

Em Goiás, restaram apenas $34,5 \%$ de cobertura vegetal nativa do Cerrado (SILVA NETO, 2018). O desmatamento avança principalmente sobre as áreas de reservas legais nas propriedades rurais do Estado, contrariando a legislação que prevê a manutenção de matas nativas. De 2000 a 2014, a área agrícola no Cerrado expandiu $87 \%$. Em torno de $70 \%$ das alterações de uso da terra ocorreram em pastagem ou em outras agriculturas. Em 25 de maio de 2012, foi aprovado o novo Código Florestal Brasileiro, que, entre suas diversas mudanças para reserva legal, autoriza ao proprietário o plantio de espécies nativas consorciadas com espécies exóticas em até $50 \%$ da área total. No código anterior, era obrigatório o plantio da reserva legal apenas com espécies nativas. Porém, ainda são escassos os estudos para comprovar que consórcios como este ainda garantam a função ambiental da reserva legal e tragam retornos para o proprietário. Para o Cerrado, que possui fitofisionomias e espécies com características muito particulares, as dificuldades de encontrar estudos relacionados são ainda maiores.

Sendo assim, este trabalho teve como objetivo analisar o crescimento em diâmetro de nove diferentes espécies nativas do cerrado com potencial para recuperação de áreas degradadas, consorciadas com quatro diferentes espécies exóticas, que são utilizadas em plantios comerciais, em uma área de reserva legal em recuperação, investigando os possíveis ganhos do sistema. 


\section{MATERIAL E MÉTODOS}

A área de estudo encontra-se na reserva legal Fazenda Entre Rios, situada em Brasília, DF. Segundo Koppen e Geiger, a classificação do clima em Brasília é Aw, característico dos climas úmidos tropicais (A), com estações secas e chuvosas bem definidas de acordo com Miguel e Sano (2019). A temperatura média da região é de $21,1^{\circ} \mathrm{C}$ e uma pluviosidade média anual de $1668 \mathrm{~mm}$.

O plantio foi realizado em janeiro de 2013 em uma área de aproximadamente 0,84 hectares, onde foi realizado o preparo do solo com subsolagem a $60-90 \mathrm{~cm}$, capina química e controle de formigas com formicida líquido antes da implantação. As covas foram abertas manualmente e adubadas com 100 gramas de NPK 05-25-15, sendo realizado o controle de formigas até o segundo ano do plantio. Na manutenção são realizadas capinas periódicas nas entrelinhas.

O experimento foi feito a partir da implantação do consórcio de espécies nativas e exóticas, onde as espécies nativas estão implantadas em blocos de espécies exóticas com espaçamento de $3 \times 3 \mathrm{~m}$, com doze indivíduos de cada espécie nativa, em consórcio com quatro espécies exóticas, distribuídas em 4 áreas diferentes (Figura 1).

Foram implantadas na área nove espécies nativas, sendo elas: Dipteryx alata Vogel (baru), Genipa americana L. (jenipapo), Caryocar brasiliense Camb. (pequi), Hymenaea courbaril L. (jatobá da mata), Aspidosperma polyneuron Muell. Arg (peroba rosa), Handroanthus impetiginosus Mattos (ipê-Roxo), Enterolobium maximum Ducke (tamboril), Sterculia foetida L. (chichá) e Copaifera langsdorffii Desf. (copaíba). As espécies nativas foram escolhidas considerando seus potenciais madeireiros, frutíferos e ecológicos.

As espécies exóticas do sistema são eucalipto (Eucalyptus sp.), teca (Tectona grandis L.), acácia (Acacia mangium Willd.) e seringueira (Hevea brasiliensis (Willd. ex A.Juss.) Müll.Arg.).

FIGURA 1. Croqui de parte da área de plantio, bloco de Eucalyptus sp. e Tectona grandis L.

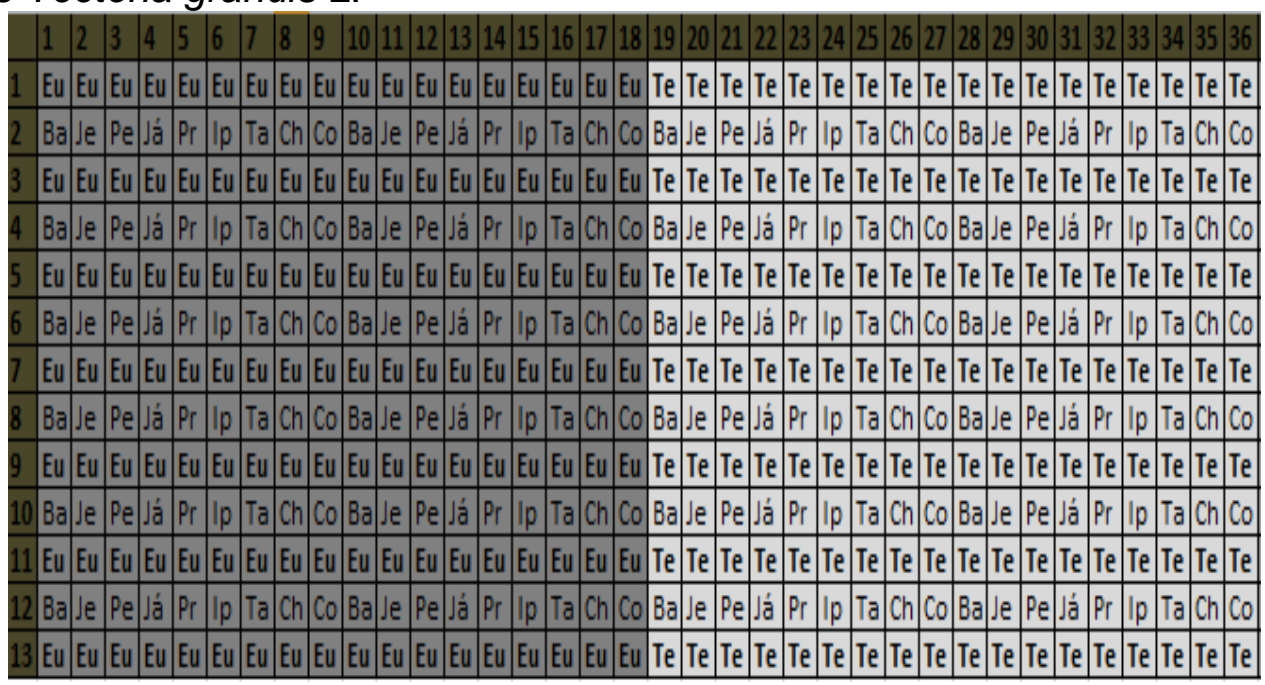

Em que: Eu-Eucalipto; Ba-Baru; Je-Jenipapo; Já-Jatobá; Pr-Peroba

Rosa; Ip-Ipê Roxo; Ta-Tamboril; Ch-Chichá; Co-Copaíba; Te-Teca. 


\section{Distribuição diamétrica}

A análise da distribuição diamétrica foi realizada a partir de dados do censo florestal realizado em julho de 2015 , onde foram obtidos altura e diâmetro de todas as espécies nativas e exóticas da área. A partir desses dados foi realizada a distribuição dos diâmetros, por área de espécie exótica e por espécie nativa dentro de cada área de espécie exótica. Assim, totalizaram quatro áreas diferentes de espécies exóticas e doze espécies nativas.

Para efetuar a distribuição diamétricas foi necessário estabelecer as classes que seriam utilizadas, sendo adotada a amplitude de um centímetro entre classes, já que os indivíduos das espécies nativas apresentaram diâmetros muito pequenos e a adoção de amplitudes maiores não representaria a população de forma adequada. Além da classe, foram definidos também o limite inferior da classe (LI), limite superior da classe (LS), valor central da classe (VC), frequência observada (FO) e frequência acumulada (FA).

\section{RESULTADOS E DISCUSSÃO}

Os diâmetros das árvores para área como um todo apresentaram média de 3,24 $\mathrm{cm}$, com diâmetro a altura do peito (DAP) mínimo de $0,1 \mathrm{~cm}$ e máximo de $15,1 \mathrm{~cm}$. Na Tabela 1 observa-se o agrupamento dos diâmetros das árvores para toda a área da reserva legal.

TABELA 1. Agrupamento dos diâmetros das espécies florestais em estudo.

\begin{tabular}{|c|c|c|c|c|c|}
\hline Classe & LI & LS & VC & $\mathrm{FO}$ & FA \\
\hline $0-1$ & 0 & 1 & 0,5 & 98 & 98 \\
\hline $1-2$ & 1 & 2 & 1,5 & 67 & 165 \\
\hline $2-3$ & 2 & 3 & 2,5 & 53 & 218 \\
\hline $3-4$ & 3 & 4 & 3,5 & 41 & 259 \\
\hline $4-5$ & 4 & 5 & 4,5 & 39 & 298 \\
\hline $5-6$ & 5 & 6 & 5,5 & 25 & 323 \\
\hline $6-7$ & 6 & 7 & 6,5 & 26 & 349 \\
\hline $7-8$ & 7 & 8 & 7,5 & 22 & 371 \\
\hline $8-9$ & 8 & 9 & 8,5 & 13 & 384 \\
\hline $9-10$ & 9 & 10 & 9,5 & 6 & 390 \\
\hline $10-11$ & 10 & 11 & 10,5 & 3 & 393 \\
\hline $11-12$ & 11 & 12 & 11,5 & 1 & 394 \\
\hline $12-13$ & 12 & 13 & 12,5 & 1 & 395 \\
\hline $13-14$ & 13 & 14 & 13,5 & 0 & 395 \\
\hline $14-15$ & 14 & 15 & 14,5 & 0 & 395 \\
\hline $15-16$ & 15 & 16 & 15,5 & 1 & 396 \\
\hline
\end{tabular}

observada; Fa: Frequência acumulada

$\mathrm{Na}$ análise da distribuição dos diâmetros nota-se que esta apresentou uma tendência em "J invertido", ou seja, a curva de distribuição diamétrica para o experimento geral apresentou grande concentração de indivíduos nas menores classes de DAP (Figura 2). 
FIGURA 2. Distribuição diamétrica de todos os indivíduos presentes na reserva legal.

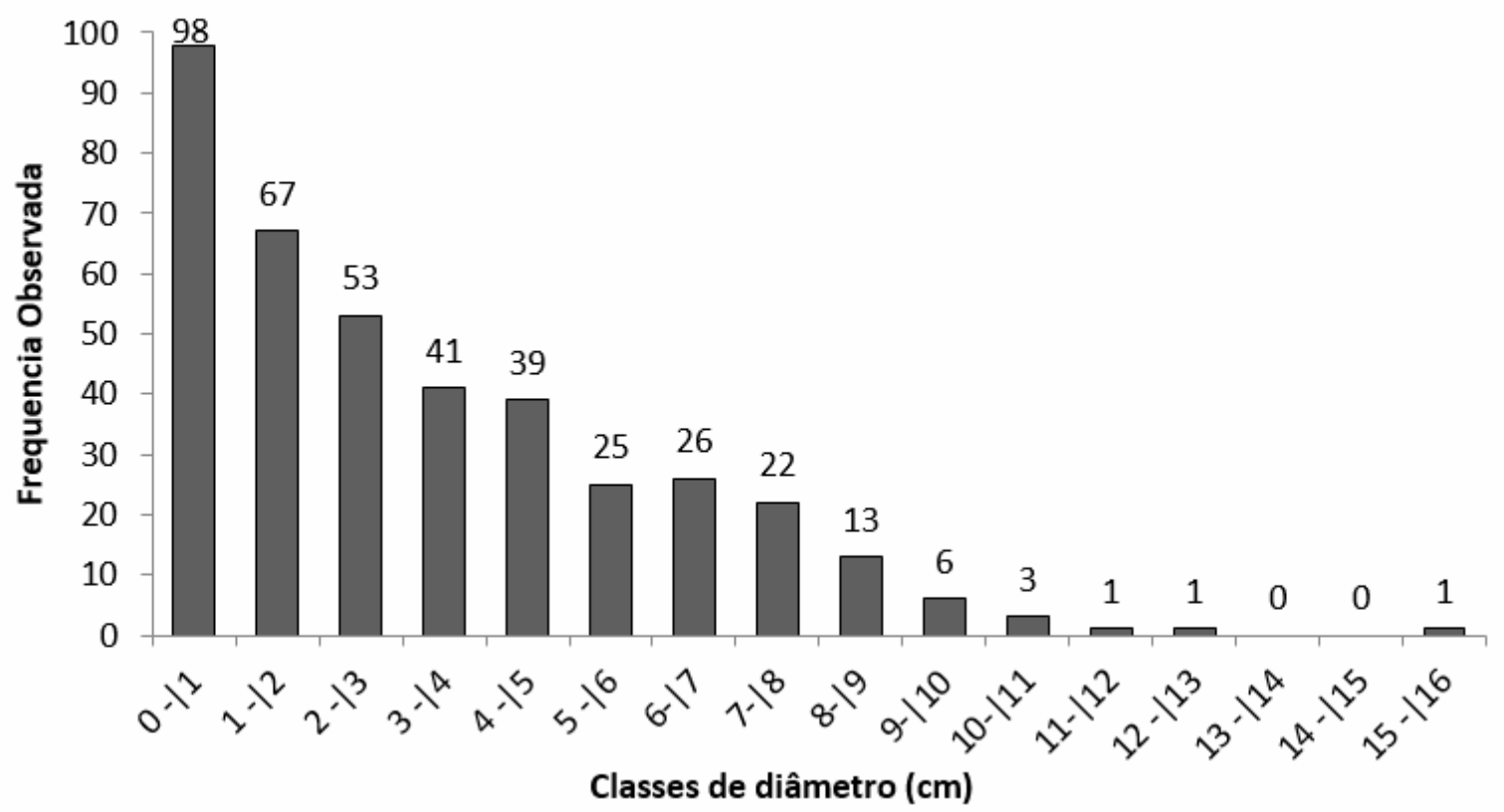

Felfili et al. (1997) ressaltaram que o formato de J-invertido apresentado pela curva de distribuição de diâmetros é um padrão considerado comum em florestas tropicais, mas se estende ao cerrado, isto se deve principalmente ao fato de que a maioria das espécies do cerrado apresenta pequeno porte. Em florestas naturais do tipo tropicais é comum que as espécies apresentem diferentes curvas de distribuições diamétricas (SILVA NETO et al., 2016a). Silva Neto et al.(2016b) ressaltaram ainda que o padrão "J-invertido" indica um balanço positivo entre recrutamento e mortalidade, sendo característico de populações auto regenerativas. Esse padrão mostra que existe uma distribuição equilibrada das diferentes classes de diâmetros e que indica o bom estado da população em estudo.

Ao realizar as análises das espécies nativas em cada bloco de espécies exóticas, verifica-se que diferentes comportamentos de acordo com a espécie exótica a que está associada. A associação das espécies nativas no bloco de Eucalyptus sp. apresentou uma distribuição diamétrica bastante equilibrada, já que os indivíduos estão distribuídos de forma mais uniforme entre as classes de diâmetro apresentadas no bloco (Figura 3). É possível destacar para o bloco de Eucalyptus sp., a Copaifera langsdorffii. e a Enterolobium maximum Ducke, sendo as espécies que possuíram comportamentos diferenciados em relação às outras espécies nativas. Os indivíduos de Copaifera langsdorffii estão presentes nas duas primeiras classes de diâmetro, ou seja, apresentaram baixo desenvolvimento das mudas implantadas. 
FIGURA 3. Distribuição diamétrica das espécies nativas consorciadas com Eucalyptus sp.

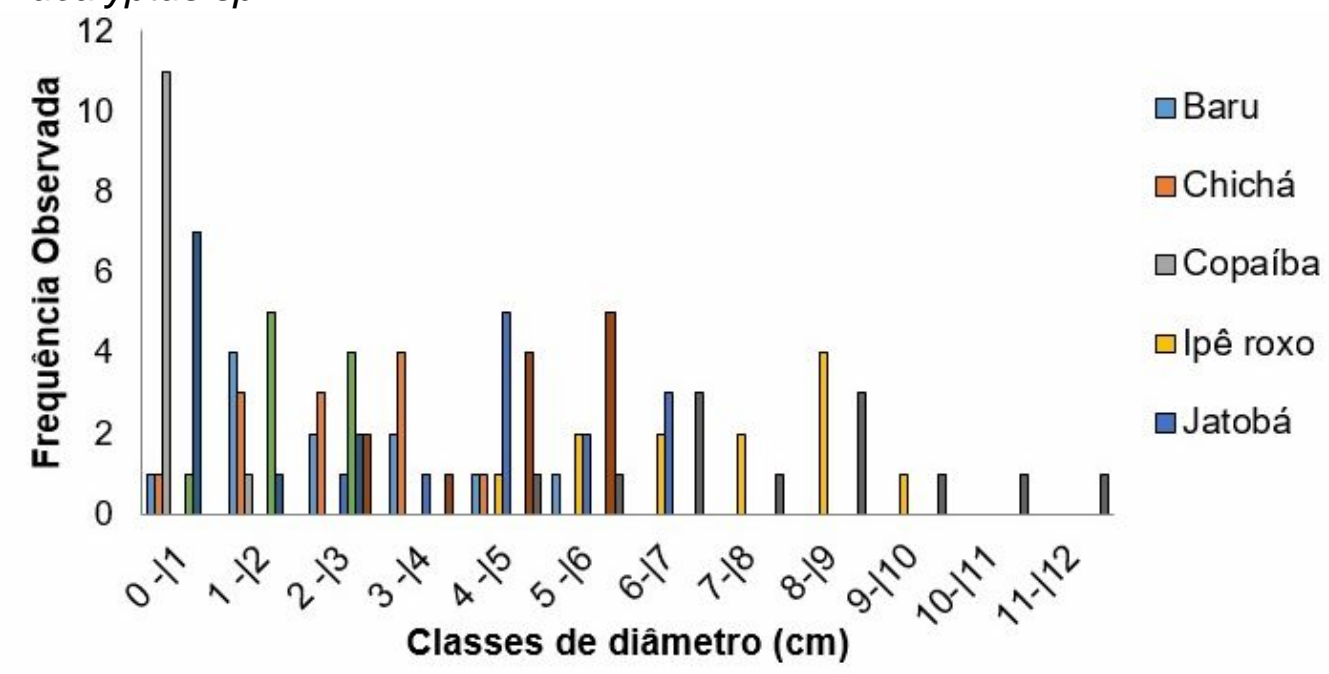

Em contraste, a espécie Enterolobium maximum não apenas apresentou os maiores valores para classes de diâmetro, como também não teve ocorrência de indivíduos nas primeiras classes. Mostrando ter tido melhor desenvolvimento quando comparado a outras espécies.

A análise das espécies nativas dentro do bloco de Tectona grandis (Figura 4) ilustra que o desenvolvimento das mesmas foi inferior ao do bloco de Eucayptus sp., pois o diâmetro máximo desse bloco apresentou menor valor quando comparado ao Eucalipto. Assim, 40\% dos indivíduos deste bloco estão presentes nas 02 primeiras classes de diâmetro, entre 0 e 2 centímetros (Figura 4). Neste bloco, destaca-se o Handroanthus impetiginosus, aparecendo somente nas últimas cinco classes de diâmetro e sendo a única espécie que alcançou a maior crescimento em diâmetro dentro do bloco, mostrando um bom desenvolvimento no consórcio com a Tectona grandis.

FIGURA 4. Distribuição diamétrica das espécies nativas consorciadas com Tectona grandis L.

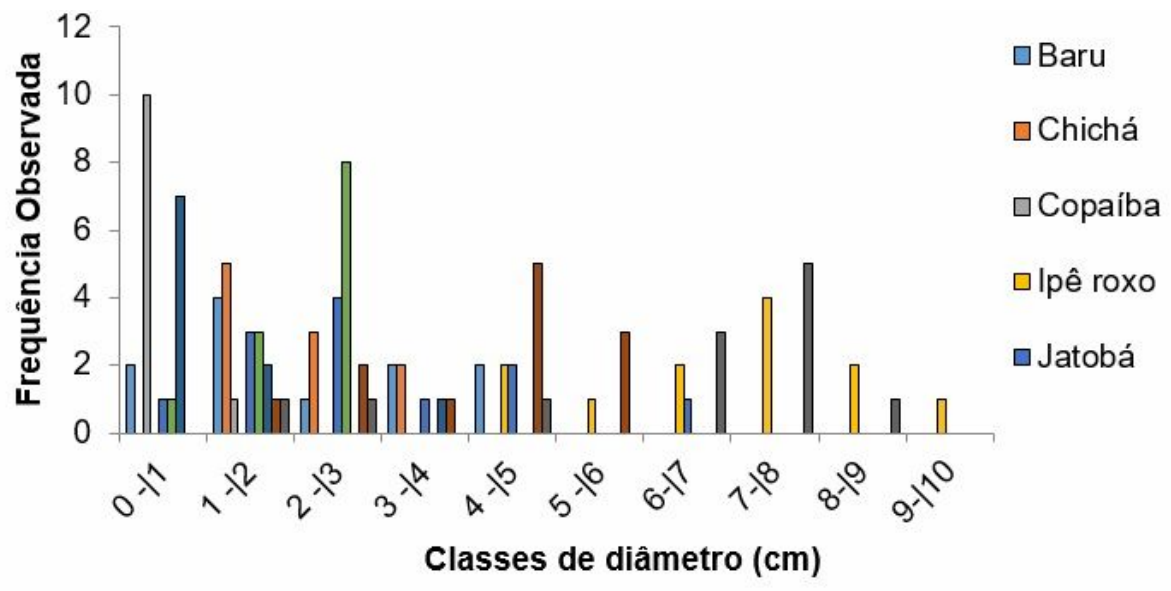


No agrupamento das espécies nativas com a Acacia mangium (Figura 5) nota-se um desenvolvimento ainda menor em relação aos outros consórcios, com uma concentração de 66,7\% das espécies até 04 centímetros de diâmetro (Figura 4). Destaca-se, neste bloco, o Caryocar brasiliense, já que foi a única espécie em que houve uma mortalidade de $66,7 \%$ dos seus indivíduos, restando apenas quatro indivíduos que não ultrapassaram 2 centímetros de diâmetro. É possível inferir que a espécie exótica neste caso está interferindo na sobrevivência e estabelecimento da espécie nativa, dificultando esses processos.

FIGURA 5. Distribuição diamétrica das espécies nativas consorciadas com Acacia mangium.

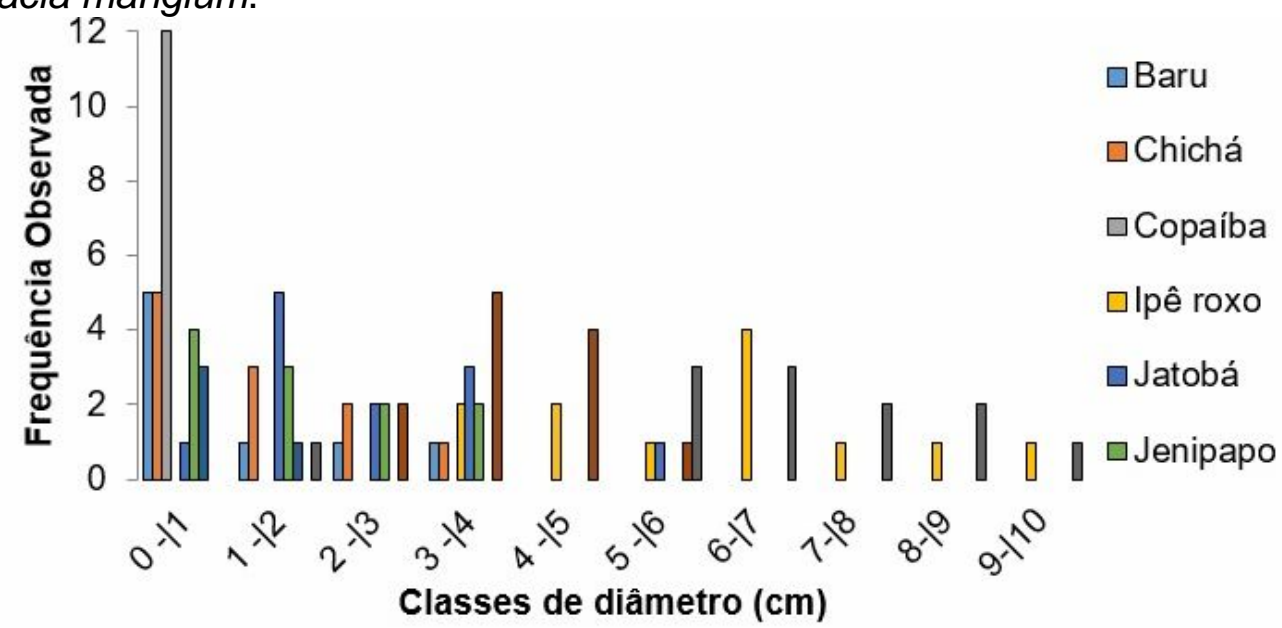

O bloco de Hevea brasiliensis associada com as espécies nativas (Figura 6), um fator destacou-se dos demais devido à maior classe de diâmetro alcançada em relação aos demais agrupamentos, e com o Enterolobium maximum Ducke chegando a 15,1 centímetros de diâmetro (Figura 6). O melhor desenvolvimento desta espécie pode ser explicado devido ao plantio da seringueira ter ocorrido mais tardiamente, quando essa e as demais espécies já estavam se estabelecendo, não havendo o sombreamento e permitindo que as mesmas crescessem a pleno sol.

FIGURA 6. Distribuição diamétrica das espécies nativas consorciadas com Hevea brasiliensis.

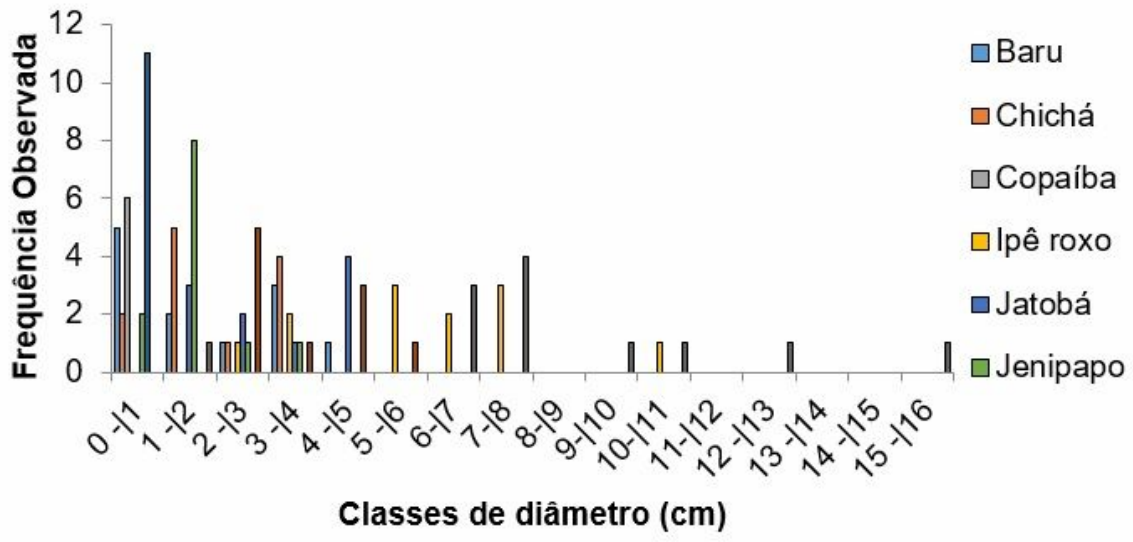


Analisando as espécies nativas separadamente, é possível inferir melhor o comportamento de cada uma em relação ao agrupamento em que foi submetida. A Copaifera langsdorffii Desf. apresentou um baixo crescimento independente do consórcio com a espécie exótica em que estava presente, atingindo somente até os dois centímetros de diâmetro (Figura 7). Ferreira et al. (2007) já estudavam a espécie, e afirmaram que a Copaifera langsdorffii Desf. é mais tolerante a sombra, característica de florestas maduras, indicando que o povoamento está se encaminhando para uma fase mais avançada de sucessão, explicando o porquê do crescimento lento da espécie em todos os blocos. Reis (2016) ao testar o desenvolvimento inicial e qualidade de mudas de Copaifera langsdorffii Desf. sob diferentes níveis de sombreamento, verificou que o melhor desenvolvimento em altura das mudas ocorre em níveis intermediários de luz, garantindo maior vantagem competitiva na ocupação de ambientes perturbados ou com degradação. Portanto, ainda segundo o autor, $50 \%$ de sombreamento para a espécie garante sua melhor sobrevivência em campo. Além dessas características, a Copaifera langsdorffi é uma espécie bastante plástica, e dependendo da floresta em que está inserida, a mesma se desenvolve de diferentes formas.

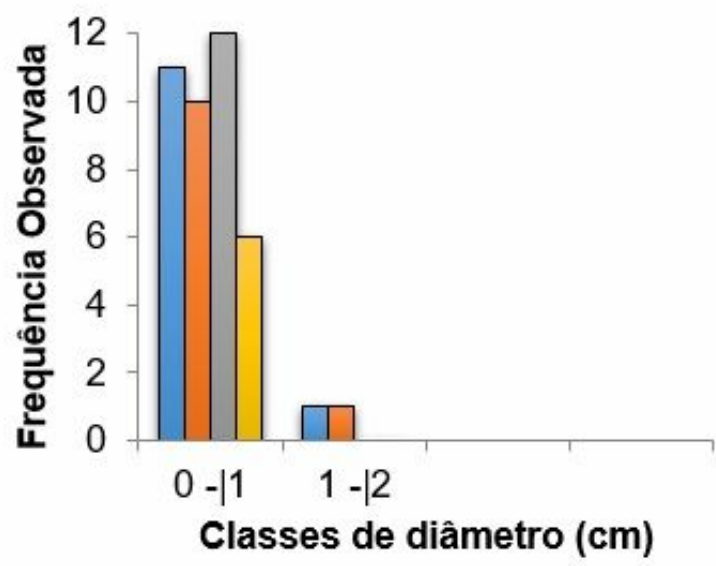

$\square$ Eucalipto $\square$ Teca $\square$ Acácia $\square$ Seringueira

FIGURA 7. Distribuição diamétrica da Copaifera langsdorffii consorciada com as diferentes das espécies exóticas.

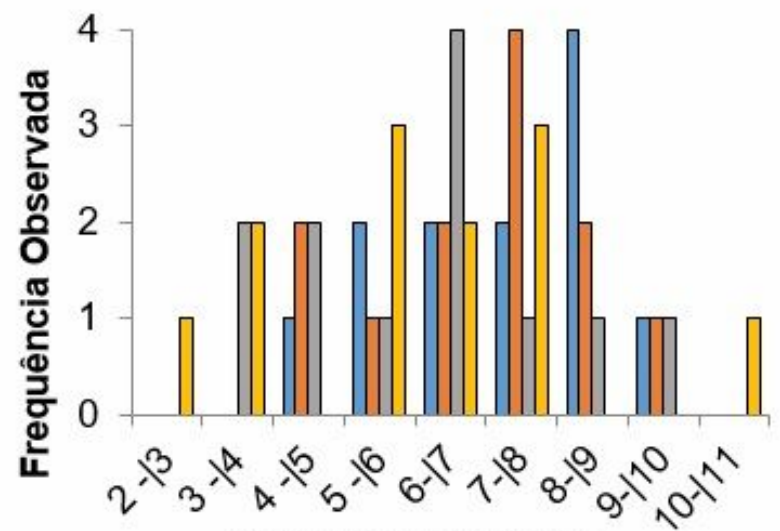

Classes de diâmetro

$\square$ Eucalipto $\square$ Teca $\square$ Acácia $\square$ Seringueira

FIGURA 8. Distribuição diamétrica da Handroanthus impetiginosus consorciada com as diferentes de espécies exóticas

Em contraste com a Copaifera langsdorffi, a Handroanthus impetiginosus obteve bom desenvolvimento, apresentando indivíduos em várias classes de diâmetros, a maioria dos mesmos estão concentrados entre 5 e 9 centímetros (Figura 8). Neste estudo, os indivíduos dessa espécie apresentaram um alcance maior no consórcio com a seringueira podendo ser explicado pelo fato de que a mesma foi implantada cerca de 4 meses após o plantio da Handroanthus impetiginosus, que já estava estabelecido, não havendo sombreamento sobre os indivíduos do mesmo.

A Dipteryx alata Vogel foi uma das espécies que diferiu no desenvolvimento de acordo com a espécie exótica em que está inserido. A Figura 9 ilustra que no consórcio 
com a Acacia mangium e Hevea brasiliensis, a maioria dos indivíduos encontram-se nas primeiras classes de diâmetro, não sendo propício para esta espécie o consórcio com essas espécies exóticas. Já nos consórcios com Tectona grandis e Eucalyptus sp. as classes de diâmetro apresentaram ampla distribuição, chegando a 5,1 centímetros no consórcio com Eucalyptus sp. Esse comportamento mostra que sua associação com esta espécie exótica oferece melhores resultados.

A Dipteryx alata mesmo apresentando melhor desenvolvimento no consórcio com Eucalyptus sp., mostrou-se com crescimento lento, podendo ser considerada característica desta espécie do cerrado. Souza et al. (2017) ao realizar uma avaliação de crescimento com mudas de Dipteryx alata e outras espécies florestais utilizadas no reflorestamento de área às margens do Rio das Almas em Ceres/GO observou, aos 270 dias após o plantio que as mudas apresentaram menores resultados no diâmetro das plantas, quando comparadas as outras espécies nativas, mostrando o crescimento lento da espécie.

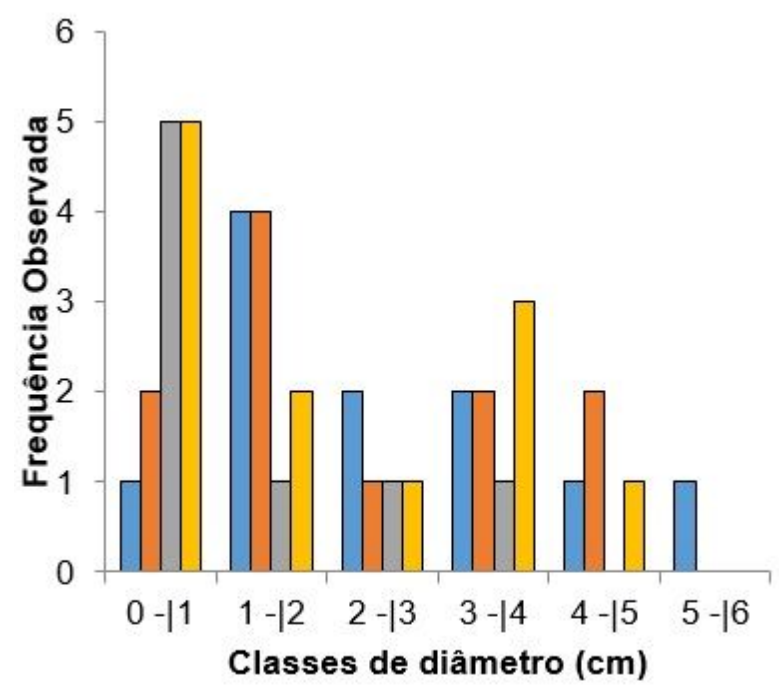

$\square$ Eucalipto $\square$ Teca $\square$ Acácia $\square$ Seringueira

FIGURA 9. Distribuição diamétrica da Dipteryx alata nos blocos de exóticas.

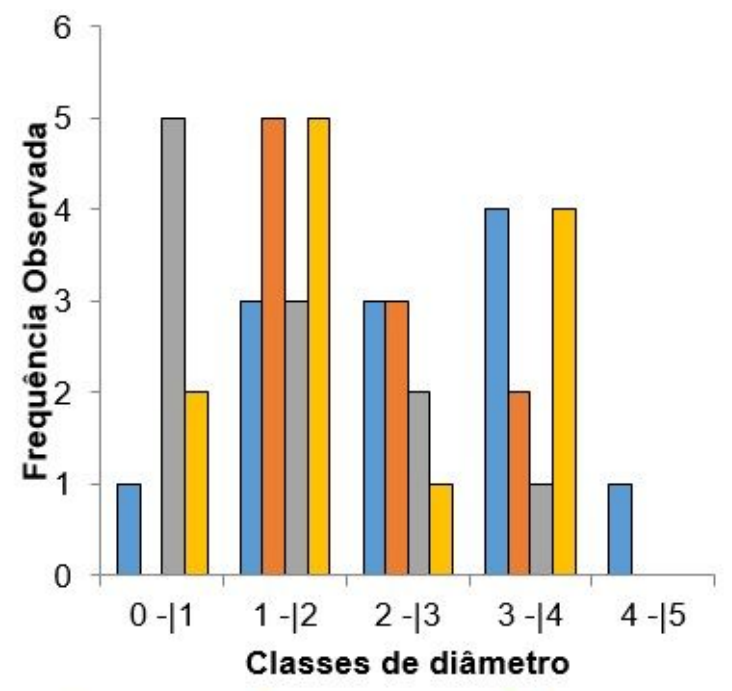

$\square$ Eucalipto $\square$ Teca $\square$ Acácia $\square$ Seringueira

FIGURA 10. Distribuição diamétrica da Sterculia foetida nos blocos de exóticas.

Assim como os indivíduos de Dipteryx alata, a Sterculia foetida L. também obteve um melhor desenvolvimento quando associado ao Eucalyptus sp. devido a sua ampla distribuição entre as classes de diâmetro e devido ao alcance de maiores classes no consórcio com essa espécie exótica (Figura 10). Ao analisar a associação da espécie com a Acacia mangium, nota-se que os indivíduos deste bloco não obtiveram crescimento satisfatório, concentrando $72 \%$ das espécies nas duas primeiras classes de diâmetro. Câmara e Endres (2008), ao analisar a diferença de crescimento em mudas de Sterculia foetida L., constatou que esta obteve melhor crescimento em 
diâmetro quando submetida a $50 \%$ de luminosidade, superando as espécies em pleno sol. Esse comportamento é observado nesse estudo, uma vez que a Tectona grandis e a Acacia mangium apresentavam amplo sombreamento, já o consorcio com Hevea brasiliensis apresentava pleno sol, fazendo com que o consórcio com Eucalyptus sp. apresentasse melhores condições.

As espécies Hymenaea courbaril L. e Aspidosperma polyneuron Muell. Arg. obtiveram melhores resultados quanto à classe diamétrica quando associadas à espécie exótica Eucalyptus sp. A Figura 11 e a Figura 12 ilustram que ambas as espécies apresentam indivíduos a partir da terceira classe de diâmetro e concentrando a maior parte dos indivíduos com mais de 4 centímetros. Pode-se inferir, a partir desse resultado com essas espécies, que o crescimento mais acelerado do eucalipto forneceu a esses indivíduos melhores condições de crescimento, e que o sombreamento não interferiu no desenvolvimento dos indivíduos de Hymenaea courbaril e Aspidosperma polyneuron.

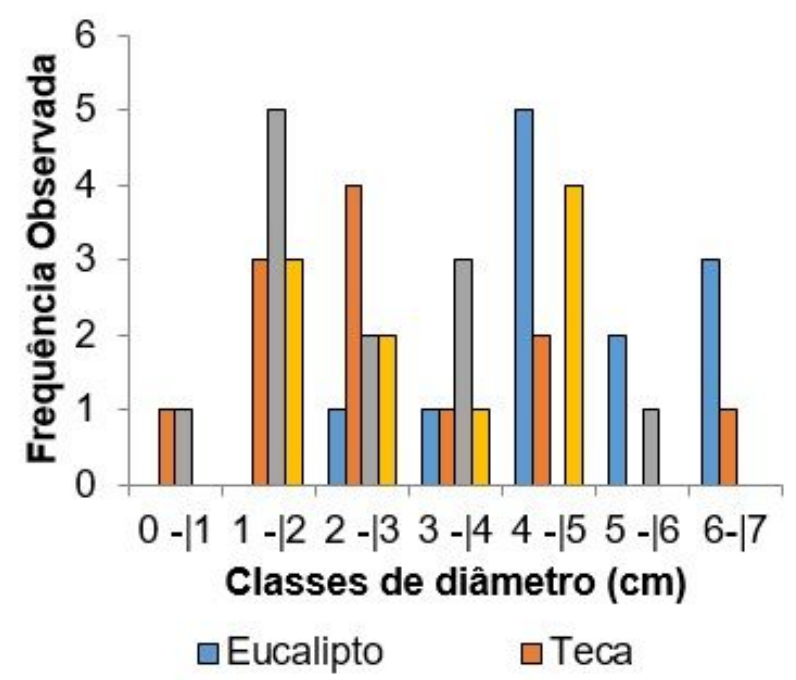

FIGURA 11. Distribuição diamétrica da Hymenaea courbaril em consorcio com espécies exóticas.

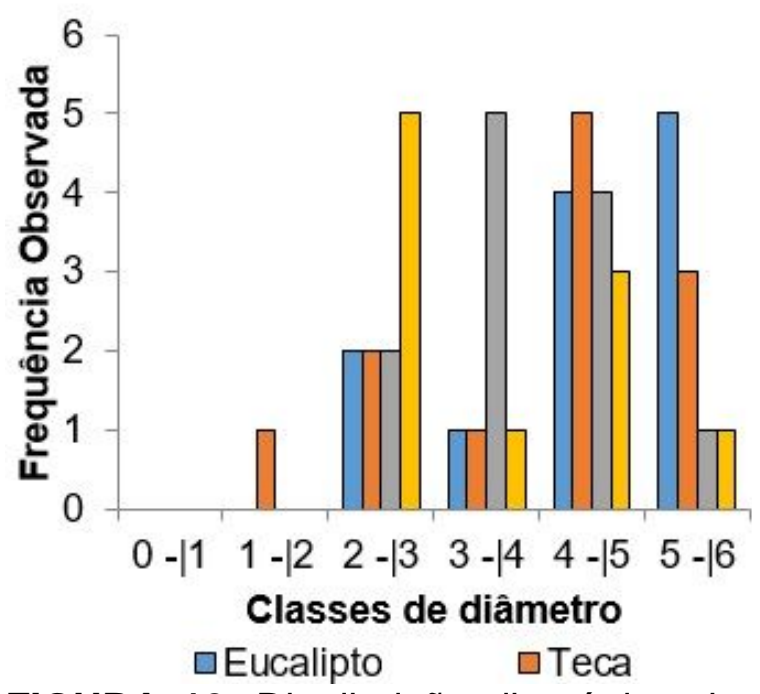

FIGURA 12. Distribuição diamétrica da Aspidosperma polyneuron nos blocos de espécies exóticas.

Em estudo realizado por Gomes e Freire (2019) com mudas de Hymenaea courbaril L. e outras espécies florestais submetidas a níveis diferentes de sombreamento, verificaram que o sombreamento de $70 \%$ promoveu a obtenção de plantas mais altas e com maiores diâmetros. De acordo com estudo realizado por Oliveira et al. (2018) as mudas de Hymenaea courbaril L. obtiveram crescimento em comprimento aéreo, radicular e em altura quando submetidas à luz contínua, sendo que a incidência não prejudicou o crescimento inicial das plantas.

Souza et al. (2001) consideram a Hymenaea courbaril L. uma espécie tipicamente de crescimento lento, que é favorecida pela sombra proporcionada pelas pioneiras. Já Aspidosperma polyneuron Muell. Arg. se mostrou mais satisfatória no ENCICLOPÉDIA BIOSFERA, Centro Científico Conhecer - Jandaia-GO, v.18 n.35; p. 225 2021 
consórcio com Eucalyptus sp., uma vez que mais indivíduos atingiram as maiores classes de diâmetro.

Segundo Felfili et al. (2002), a Genipa americana L. é considerada uma espécie pioneira ou de crescimento rápido, sendo natural de áreas de cerrado e cerradão. Esta característica não foi observada nos indivíduos de Genipa americana L., uma vez que o diâmetro máximo alcançado por esta espécie foi de 3,6 centímetros, quando associado com Acacia mangium (Figura 13). Porém, de acordo com Neves et al. (2016), a Genipa americana L. pode ser considerada espécie de crescimento moderado e que consegue tolerar sombreamento moderado. Neste estudo, a Genipa americana L. não pode ser considerada uma espécie apta a ser consorciada com espécies exóticas, pois não apresentou crescimento satisfatório em nenhum dos experimentos, com crescimento muito lento em relação as características da espécie.

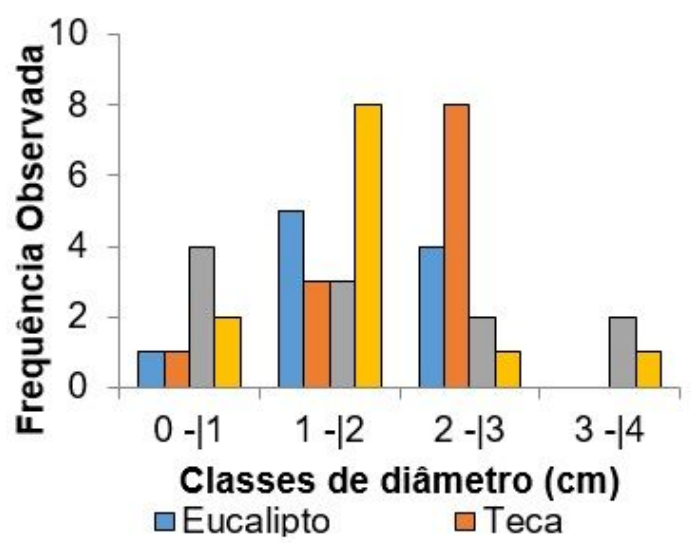

FIGURA 13. Distribuição diamétrica do Genipa americana no consórcio com espécies exóticas.

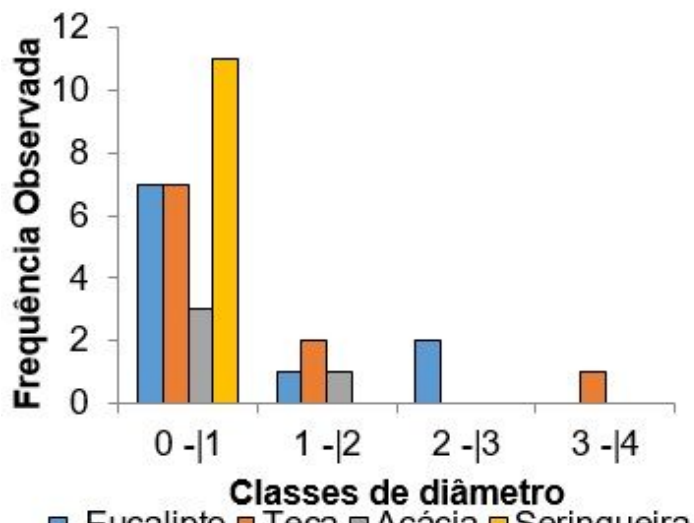

$\square$ Eucalipto $\square$ Teca $\square$ Acácia $\square$ Seringueira Caryocar brasiliense no consórcio com espécies exóticas.

Assim como a Genipa americana L., a Caryocar brasiliense Camb. não apresentou um desenvolvimento satisfatório em nenhum dos blocos do experimento (Figura 15). Porém, a Caryocar brasiliense Camb., diferentemente da Genipa americana L., possui característica de crescimento mais lento. Oliveira (2006) observou, em um plantio com 19 espécies nativas do bioma cerrado para recuperação, onde a Caryocar brasiliense Camb., em doze meses de avaliação, teve incremento de $0,9 \mathrm{~cm}$ para 1,5 $\mathrm{cm}$ de diâmetro, ou seja, crescimento muito lento. Outro fator que dificultou o desenvolvimento do Caryocar brasiliense foi a mortalidade das mudas, por exemplo, no bloco de Acacia mangium, em que $66,67 \%$ dos indivíduos desta espécie não sobreviveram.

A Enterolobium maximum Ducke foi à espécie que alcançou os maiores valores de diâmetros no experimento, tendo bom desenvolvimento quando plantado em consórcio com todas as espécies exóticas (Figura 15). D’Abadia et al. (2017) afirmam que o tamboril é uma espécie que possui grande porte, além de ter crescimento rápido podendo alcançar 35 metros de altura. No entanto, seu crescimento é destacado nos 
blocos de Eucalyptus sp. e Hevea brasiliensis, sendo que neste último apresentou valores máximos dentro do experimento. É possível inferir que o seu melhor desenvolvimento com a Hevea brasiliensis é devido a esta ter sido implantada posteriormente, fazendo que seu crescimento ocorresse a pleno sol, o que não ocorreu com Eucalyptus sp., que cresceu de forma acelerada e sombreou as mudas.

FIGURA 15. Distribuição diamétrica da Enterolobium maximum consorciada com as espécies exóticas.

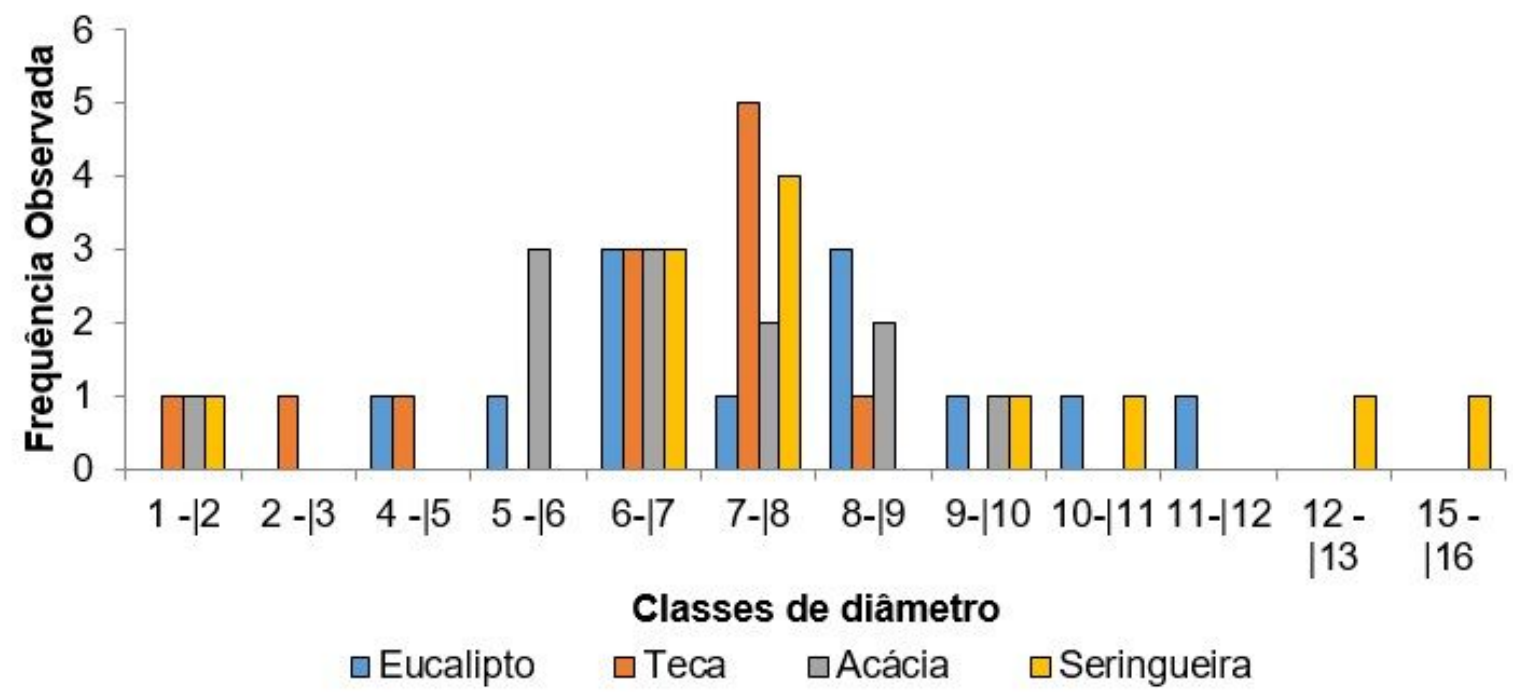

\section{CONCLUSÃO}

O consórcio das espécies nativas com Eucalyptus sp. se mostrou o mais satisfatório, devido ao melhor desenvolvimento das espécies no crescimento em diâmetro, sendo um agrupamento viável para plantios que visem à restauração florestal. Em contraste, o consórcio de espécies nativas com Acacia mangium não foi satisfatório, devido à alta taxa de mortalidade das espécies nativas e do crescimento lento das mesmas, sendo recomendados estudos específicos dos indivíduos de Acacia mangium, neste experimento, para que seja possível inferir a razão desse crescimento insatisfatório.

Ao analisar as espécies nativas individualmente, as espécies de Enterolobium maximum e Handroanthus impetiginosus foram as que apresentaram um melhor desenvolvimento quando consorciadas com as exóticas. Já a Copaifera langsdorffii e a Caryocar brasiliense foram às espécies que apresentaram o crescimento mais lento entre as demais, porém, é importante a implantação de espécies com características complementares para enriquecer o plantio e garantir a recuperação da floresta.

A possibilidade de plantio de espécies exóticas para corte faz com que a recuperação se torne mais atrativa ao produtor rural. Esse estudo mostrou que a 
mudança do código florestal permitindo o consórcio de espécies exóticas e nativas é interessante tanto para promover a recuperação da reserva legal, quanto para gerar renda a produtor, ou seja, viável economicamente e ambientalmente.

\section{REFERÊNCIAS}

CÂMARA, C. A.; ENDRES, L. DESENVOLVIMENTO DE MUDAS DE DUAS ESPÉCIES ARBÓREAS: Mimosa caesalpiniifolia Benth. E Sterculia foetida L. sob diferentes níveis de sombreamento em viveiro. Floresta, Curitiba, v. 38, n. 1, p.43-51, mar/ 2008.

CARNEIRO FILHO, A.; COSTA, K. A expansão da soja no Cerrado: Caminhos para a ocupação territorial, uso do solo e produção sustentável. São Paulo, Agroicone, p. p130, 2016. Disponível em: <https://www.inputbrasil.org/wp-content/uploads/2016/11/AExpans\%C3\%A3o-da-Soja-no Cerrado_Agroicone_INPUT.pdf>.

D'ABADIA, K. L., MORAIS, Y. C. R., CUNHA, S. D., COELHO, G. M., ARAÚJO, M. S. Efeito do tempo de embebição na germinação e crescimento inicial de plântulas de tamboril. Ipameri. Anais da Semana de Ciências Agrárias e Jornada de PósGraduação em Produção Vegetal. Universidade Estadual de Goiás, v.14, p. 109-114, 2017. Disponível em: <https://www.anais.ueg.br/index.php/seciag/article/view/9422>.

FELFILI, J. M.; SANTOS, A. A. B. Direito ambiental e subsídios para a revegetação de áreas degradadas no Distrito Federal. Universidade de Brasília/Departamento de Engenharia Florestal. Comunicações técnicas florestais, v. 4, n. 2, Brasília, 2002. 135p. Disponível em: <https://books.google.com.br/books/about/Direito_ambiental_e_subsidios_para_a_rev.h tml?id=zKk8YAAACAAJ\&redir_esc $=y>$.

FELFILI, J. M.; SILVA JÚNIOR, M. C.; NOGUEIRA, P. E.; MARIMON, B. S.; DELITTI, W. B. C. 1997. Comparação florística e fitossociológica do cerrado nas Chapadas Pratinha e dos Veadeiros. In Contribuição ao conhecimento ecológico do Cerrado (L.L. Leite, C.H. Saito, eds.) Editora Universidade de Brasília, Brasília, p. 6-11.

FERREIRA, W. C.; BOTELHO, S. A.; DAVIDE, A. C.; FARIA, J. M. R. Avaliação do crescimento do estrato arbóreo de área degradada revegetada à margem do Rio Grande, na Usina Hidrelétrica de Camargos, MG. Revista Árvore [online]. 2007, v.31, n.1, p.177-185,2007. Disponível em: <https://www.scielo.br/scielo.php?pid=S010067622007000100020\&script=sci_abstract\&tlng=pt>. doi: https://doi.org/10.1590/S010067622007000100020.

GOMES, A. D. V.; FREIRE, A. L. O. Crescimento e qualidade de mudas de cedro (Cedrela fissilis L.) em função do substrato e sombreamento. Scientia Plena, v. 15, n. 11, 2019.

MACHADO, R. B.; NETO, M. B. R.; PEREIRA, P. G. P.; CALDAS, E. F.; GONÇALVES, D. A.; et. al. 2004. Estimativas de perda da área do Cerrado brasileiro. Conservação 
Internacional, Brasília, DF. Disponível em: <http://cmbbc.cpac.embrapa.br/RelatDesmatamCerrado\%20CIBrasil\%20JUL2004.pdf>.

MIGUEL, B. S.; SANO, E. E. Classificação do uso e cobertura da terra do Distrito Federal, Brasil, a partir de dado de coerência interferométrica. Revista Brasileira de Geografia Física, v. 12, n. 02, p. 427-442, 2019.

NEVES FILHO, D. F.; DE SÁ LAURO, C. Implantação e avaliação de mudas nativas em um solo degradado no município de Quirinópolis, Goiás. 2016. Trabalho de Conclusão de Curso (Bacharelado em Engenharia Ambiental) - Universidade de Rio Verde, Rio Verde, 2016. Acesso em: 7 fev. 2021.

OLIVEIRA, M. C. P.; RODRIGUES, B. S.; CARVALHO, C. S.; NASCIMENTO, M. S.; SANTOS, S. S.; et al. Crescimento inicial e estoque de carbono de Hymenaea Courbaril I. Var. Stilbocarpa (hayne) lee et lang. Educação Ambiental em Ação, v. 17, n. 64, 2018.

REIS, S. M.; MARIMON-JÚNIOR, B. H.; MORANDI, P. S.; OLIVEIRA-SANTOS, C.; OLIVEIRA, B.; et al. Desenvolvimento inicial e qualidade de mudas de Copaifera langsdorffii Desf. sob diferentes níveis de sombreamento. Ciência Florestal, v. 26, n. 1, p. 11-20, 2016.

SILVA NETO, F. P. Diagnóstico do uso da terra e avaliação das legislações ambientais em municípios pertencentes ao cerrado goiano. Trabalho de Conclusão de Curso (Bacharelado em Agronomia) - Centro Universitário de AnápolisUniEVANGÉLICA, 2018. Acesso em: 7 fev. 2021.

SILVA NETO, V. L.; OLIVEIRA, A. L.; FERREIRA, R. Q. S.; SOUZA, P. B.; VIOLA, M. R. Fitossociologia e distribuição diamétrica de uma área de Cerrado sensu stricto, DueréTO. Revista de Ciências Ambientais, v. 10, n. 1, p. 91-106, 2016a.

SILVA NETO, V. L.; OLIVEIRA, A. L.; SANTOS, A. F.; LOURENÇO, S. T. S. Distribuição diamétrica e estrutura fitossociológica de cerrado sensu stricto em GurupiTO. Enciclopédia Biosfera, v. 13, n. 23, $2016 \mathrm{~b}$.

SOUZA, C. S.; MOTA, D. S.; FARIA, B. P.; NETO, J. L. R.; BRAVO, D. P.; et al. Crescimento Inicial de Espécies Utilizadas na Recuperação de Mata Ciliar no Rio das Almas, Município de Ceres, Goiás. 2017. Disponível em: <https://www.researchgate.net/publication/320725198_Crescimento_Inicial_de_Especie s_Utilizadas_na_Recuperacao_de_Mata_Ciliar_no_Rio_das_Almas_Municipio_de_Cer es_Goias>. doi: 10.19180/2177-4560.v11n12017p75-92.

SOUZA, P. A.; VENTURIN, N.; MACEDO, R. L. G., ALVARENGA, M. I. N., SILVA, V. F. Estabelecimento de espécies arbóreas em recuperação de área degradada pela extração de areia. Revista Cerne, Lavras, v. 7, n. 2, p. 043- 052, 2001. 
STRASSBURG, B. B. N.; BROOKS, T.; FELTRAN-BARBIERI, R.; IRIBARREM, A.; CROUZEILLES, R. et al. Moment of truth for the Cerrado hotspot. Nature Ecology \& Evolution, v. 1, 0099 (2017). 